\title{
Corrections for downhole NMR logging
}

\author{
Hu Haitao, Xiao Lizhi* and Wu Xiling \\ State Key Laboratory of Petroleum Resource and Prospecting, China University of Petroleum, Beijing 102249, China \\ (C) China University of Petroleum (Beijing) and Springer-Verlag Berlin Heidelberg 2012
}

\begin{abstract}
Nuclear magnetic resonance logging (NMR) is an open well logging method. Drilling mud resistivity, formation resistivity and sodium ions influence its radio frequency (RF) field strength and NMR logging signals. Research on these effects can provide an important basis for NMR logging data acquisition and interpretation. Three models, water-based drilling mud-water bearing formation, waterbased drilling mud - oil bearing formation, oil-based drilling mud - water bearing formation, were studied by finite element method numerical simulation. The influences of drilling mud resistivity and formation resistivity on the NMR logging tool RF field and the influences of sodium ions on the NMR logging signals were simulated numerically. On the basis of analysis, RF field correction and sodium ion correction formulae were proposed and their application range was also discussed. The results indicate that when drilling mud resistivity and formation resistivity are $0.02 \Omega \cdot \mathrm{m}$ and $0.2 \Omega \cdot \mathrm{m}$ respectively, the attenuation index of centric NMR logging tool is $8.9 \%$ and $9.47 \%$ respectively. The RF field of an eccentric NMR logging tool is affected mainly by formation resistivity. When formation resistivity is 0.1 $\Omega \cdot \mathrm{m}$, the attenuation index is $17.5 \%$. For centric NMR logging tools, the signals coming from sodium ions can be up to $31.8 \%$ of total signal. Suggestions are proposed for further research into NMR logging tool correction method and response characteristics.
\end{abstract}

Key words: NMR logging, finite element method, RF field, NMR signal, formation resistivity, sodium ions

\section{Introduction}

Nuclear magnetic resonance (NMR) logging (Coates et al, 1999 ) is an open hole logging technique, which can provide effective porosity (Xie et al, 2006; 2008; Wang et al, 2006), free fluid porosity, bound water porosity, pore size distribution and permeability. It contains no contribution from the matrix materials and does not need to be calibrated for formation lithology. The first step of making an NMR measurement is to polarize magnetic nuclei in the formation with a static magnetic field $B_{0}$ and then these magnetic nuclei are excited by radio frequency (RF) field $B_{1}$ generated by antenna which is also used to receive the NMR signal. These NMR data can be used for evaluating oil and gas resources. However, the resistivity of drilling mud in the borehole and formation fluid has an influence that cannot be ignored on the NMR logging RF field when NMR logging tool is being used downhole. This is because low resistivity drilling mud and formation fluid have good electrical conductivity, which has significant attenuation effects on the NMR logging tool RF field and leads to low antenna efficiency, low gain and low antenna $Q$ (Chen and Hursan, 2010). In general, low resistivity drilling mud and formation fluid are due to the high salinity of drilling mud and formation fluid which contain sodium ions that will

*Corresponding author. email: xiaolizhi@cup.edu.cn

Received April 26, 2011 also produce an NMR signal (Headley, 1973; Ferris et al, 1993). On the one hand, sodium NMR signals decrease the NMR logging signal to noise ratio (SNR); while on the other hand, sodium NMR signals add to the hydrogen NMR signals, which can result in an overestimate of the porosity calculated from NMR logging data (Xiao, 2007). For the MRIL-C NMR logging tool, the research results showed that a high salinity borehole had little effect on the electromagnetic waves and more influences on antenna $Q$. Sodium ions had influences on fast-decay components in $T_{2}$ distribution, and these effects could be eliminated with software or fluid excluder, but the latter reduced the performance of the tool (Mardon et al, 1995). So for the new centric and eccentric NMR logging tools, researching the influence of borehole fluid resistivity on the NMR logging RF field, analyzing the influence of sodium ions on NMR logging signals, and developing corresponding correction methods have great significance to increase the SNR (Xie et al, 2010) of NMR logging data, heighten the effect of NMR logging application in the oil industry, and develop new techniques (Sun and Dunn, 2005; Xie and Xiao, 2009) and data inversion of NMR logging (Xiao et al, 2009; Sun et al, 2009; 2010).

In this paper, corresponding models were established for researching the influence of drilling mud resistivity and formation resistivity on centric and eccentric NMR logging tools, and corresponding correction equation was developed, the application range was also discussed. In addition, the influence mechanism of sodium ions on NMR logging 
signals was analyzed, and the relevant correction method was developed based on numerical simulation.

\section{Establishing models and analysis of factors affecting NMR logging response}

\subsection{Numerical simulation theory and model establishment}

In this paper, the influences of drilling mud resistivity and formation resistivity on NMR logging tools were analyzed by electromagnetic field finite element method (FEM) numerical simulation. According to Maxwell equations vector $\vec{A}$ is defined as

$$
\vec{B}=\nabla \times \vec{A}=\frac{\partial A_{z}}{\partial y} i-\frac{\partial A_{z}}{\partial x} j
$$

where $\vec{B}$ is the magnetic flux density; $\vec{A}$ is the vector potential. Assuming computational domain is $\Omega$, and boundary is $\Gamma$, the problem satisfies known boundary conditions $\left.A_{z}\right|_{\Gamma_{1}}=A_{z 0}$ and vector potential $\vec{A}$ satisfies $\left.\frac{\partial A_{z}}{\partial n}\right|_{\Gamma_{2}}=-\mu H_{t}$. The following functional can be obtained by variational principle

$$
\begin{aligned}
\Omega: \Pi(\vec{A})= & \left\{\iint_{\Omega} \frac{1}{2 \mu}\left[\left(\frac{\partial \vec{A}}{\partial x}\right)^{2}+\left(\frac{\partial \vec{A}}{\partial y}\right)^{2}\right]-J_{z} \vec{A}\right\} \mathrm{d} x \mathrm{~d} y \\
& +\int_{\Gamma_{2}} H_{t} \vec{A} \mathrm{~d} l=\min
\end{aligned}
$$

$\Gamma_{1}: \vec{A}=A_{0}$

where $H_{t}$ is a tangential component of magnetic field intensity; $\mu$ is magnetic permeability; $J$ is electric current density vector.
The FEM is used to discretize computational domain $\Omega$, and the global equation is finally obtained

$$
[K]\{\vec{A}\}=\{R\}
$$

where $[K]$ is coefficient matrix; $\{\vec{A}\}$ is the solution matrix; $\{R\}$ is the known matrix. The vector potential $\vec{A}$ can be obtained by solving Eq. (3), and the magnetic flux density $\vec{B}$ is obtained from Eq. (1).

As shown in Fig. 1, NMR logging tools can be classified as centric (Prammer et al, 2001) and eccentric (Reiderman and Beard, 2003) according to their working mode. When the centric NMR logging tool is down the borehole, the NMR sensor is situated in the center of borehole and NMR sensor shell does not contact the borehole wall, so drilling mud is present between the NMR sensor shell and the borehole wall. Drilling mud conductivity has great influence on the detection performance of NMR logging tool sensors. This is because the NMR logging tool RF field is an alternating electromagnetic field. Low resistivity drilling mud will directly attenuate the RF field, and then RF field strength in sensitive volume may not reach the required level for tipping magnetization. As a result, drilling mud resistivity $R_{\mathrm{m}}>0.02 \Omega \cdot \mathrm{m}$ is required for centric NMR logging tools. The active part of the sensor of the eccentric NMR logging tool is held in contact with the borehole wall by pressure against the opposite side of the borehole. There is no or a little drilling mud between them, so the eccentric NMR logging tool is almost immune to drilling mud resistivity. However, if the formation is water bearing, the measurements of NMR logging will still be affected.

Because oil and gas have high resistivity, their influence on the NMR RF field can be ignored. Here, three models, water-based drilling mud-water bearing formation, waterbased drilling mud-oil bearing formation, oil-based drilling mud - water bearing formation, were analyzed.

As an open hole logging technique, the distance of

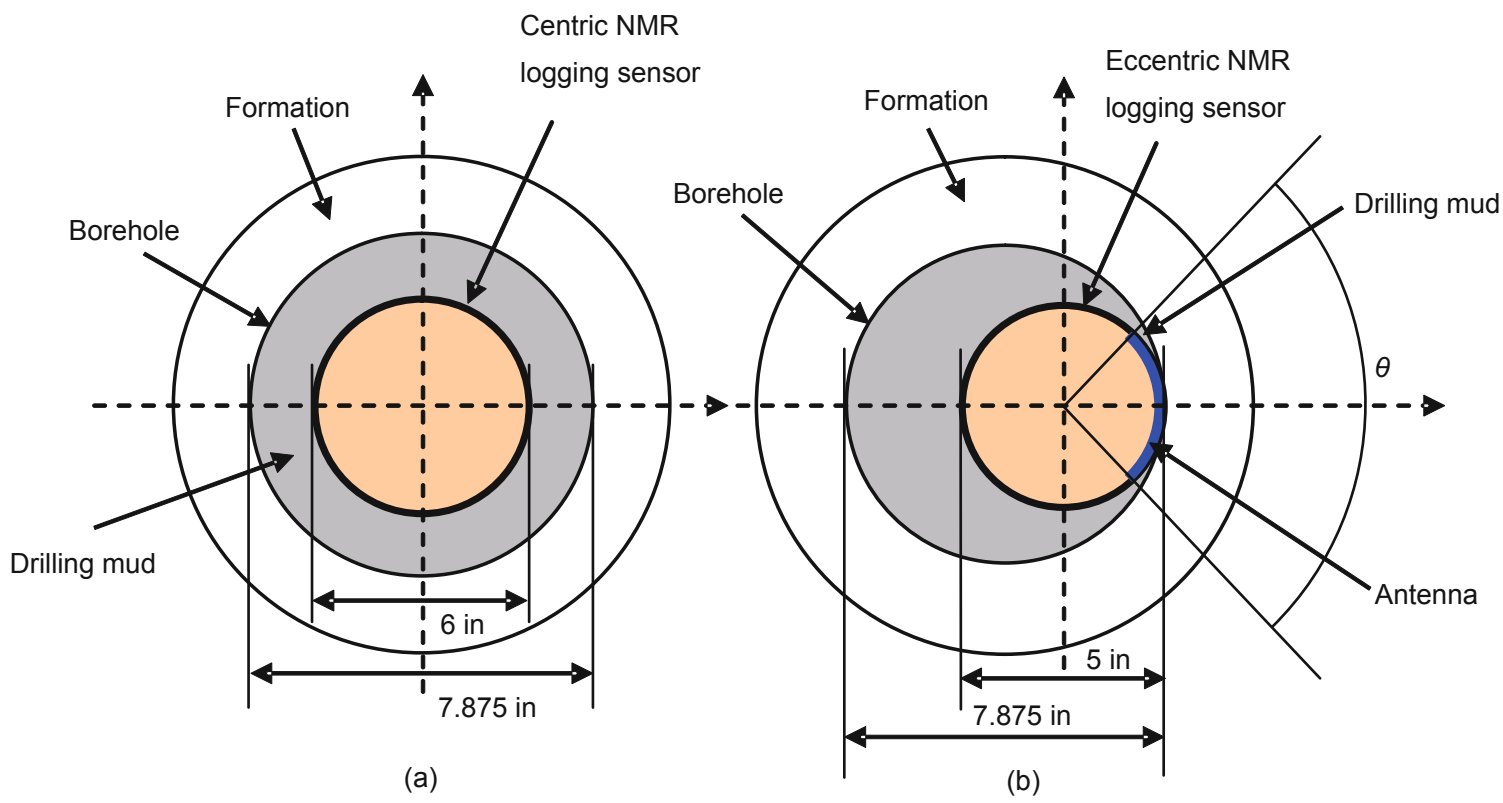

Fig. 1 The working mode of NMR logging tools (a) Centric NMR logging tool; (b) Eccentric NMR logging tool 
investigation (DOI) of NMR logging tools does not exceed $12 \mathrm{~cm}$. After formation invasion, the DOI is contained in the flush zone. The distance and extent of formation invasion increases with the passage of time, so models analyzed in this paper are established at formation invasion start and formation invasion end. The models established at formation invasion start are applied to NMR logging while drilling, and the models established at formation invasion end are applied to NMR logging when the formation invasion extent exceeds the DOI of NMR logging tools.

\subsection{The influence of drilling mud resistivity and formation resistivity on the NMR logging tool RF field}

2.2.1 Water-based drilling mud-water bearing formation

Water-based drilling mud is widely used, both onshore and offshore. Especially for offshore drilling, water-based drilling mud is drilling engineers' favorite choice. However, because it has low resistivity, the measurements of some logging tools will be affected, for example, electric logging, electromagnetic logging, and NMR logging, and these influences should not be ignored.

(a) For centric NMR logging tools, because drilling mud and formation are present within the sensitive volume, the water-based drilling mud-water bearing formation model is analyzed.

(b) When eccentric NMR logging tools are used, there is little or no drilling mud existing between the NMR sensor shell and borehole wall, so the influence of drilling mud resistivity on RF field is less. However, because the eccentric NMR logging tool antenna has a wide angle and the size of borehole is bigger than NMR sensor size, as shown in Fig. 1(b), a part of the RF field has to penetrate drilling mud and to get to the formation, so drilling mud still has some influence on the eccentric NMR RF field.

\subsubsection{Water-based drilling mud-oil bearing formation}

For this model, the main factor is water-based drilling mud. Because of the high resistivity of oil bearing formation, it has little influence on the RF field, and the oil bearing formation can be treated as air in numerical simulation. The water drilling mud influences centric NMR logging tools, and according to above-mentioned analysis, this model still has some influence on the eccentric NMR logging tool.

\subsubsection{Oil-based drilling mud-water bearing formation}

For a centric NMR logging tool, low resistivity waterbearing formation has influence on its RF field. For eccentric NMR logging tool, this model has influence on it too because the eccentric NMR logging tool RF field still has to penetrate formation within the sensitive volume.

\subsection{The influence of sodium ions in drilling mud and formation fluid on NMR logging porosity}

During the measurement of NMR logging, when $B_{0}$ is imposed on magnetic nuclei, the nuclei will precess around $B_{0}$. The precession frequency $(f)$, called the Larmor frequency, is given by

$$
f=\frac{\gamma B_{0}}{2 \pi}
$$

where $\gamma$ is the gyromagnetic ratio, which is a measure of the strength of the nuclear magnetism. For hydrogen, $\gamma / 2 \pi=$ 42.58 MHz/T; for sodium, $\gamma / 2 \pi=11.262 \mathrm{MHz} / \mathrm{T}$.

The centric NMR static field is a gradient field, which reduces with distance from the tool. When DOI is $8 \mathrm{~cm}$, the static field strength is $1.8 \times 10^{-2} \mathrm{~T}$, and the operation frequency is $766 \mathrm{kHz}$. According to Eq. (4), the static field strength of sodium ions on resonance is about $6.8 \times 10^{-2} \mathrm{~T}$. So, if drilling mud and formation fluid rich in sodium exist near the NMR logging tool shell, the sodium ions will produce NMR signals which are added to the hydrogen NMR signals. This not only decreases the NMR logging signal-to-noise ratio (SNR) but also leads to the porosity calculated from NMR logging data being an overestimate. So, proper correction is required to eliminate the influence and improve the accuracy of NMR logging porosity.

\section{Numerical simulation and correction method of NMR logging response}

\subsection{Centric NMR logging tools}

The centric NMR logging tool is called MRIL-P by the Halliburton Company. This tool has a gradient magnetic field produced by a cylindrical permanent magnet and this static field is distributed symmetrically around the borehole. The sensitive volume of MRIL-P is a thin cylinder which contains omnidirectional information from a $360^{\circ}$ view around the borehole ( $\mathrm{Hu}$ and $\mathrm{Xiao}, 2010)$. Its DOI is about $8-12 \mathrm{~cm}$. The magnetic field distribution can be obtained by FEM numerical simulation ( $\mathrm{Hu}$ et al, 2011). Fig. 2 shows the simulation results of RF field distribution as a function of distance without the influence of drilling mud and formation. When DOI is $8 \mathrm{~cm}$, the RF field strength is $5.26 \times 10^{-4} \mathrm{~T}$. NMR logging uses the Carr-Purcell-Meiboom-Gill (CPMG) sequence to measure the formation fluid. The RF pulse should rotate the net magnetization vector $90^{\circ}$ or $180^{\circ}$. The angle through which the magnetization is tipped is given by

$$
\theta_{0}=\gamma B_{1} t_{\mathrm{p}}
$$

where $B_{1}$ is RF field strength; $t_{\mathrm{p}}$ is time over which the oscillating field is applied.

Formation resistivity $\left(R_{\mathrm{xo}}\right)$ is set to $0.1,0.2,1,10,100$ and $500 \Omega \cdot \mathrm{m}$ respectively; drilling mud resistivity $\left(R_{\mathrm{m}}\right)$ is set to $0.001,0.005,0.01,0.02,0.05,0.1,1,10$ and $100 \Omega \cdot \mathrm{m}$ respectively. The model shown in Fig. 1(a) is analyzed by FEM numerical simulation. The corresponding simulation results of the NMR logging tool RF field in these conditions are shown in Fig. 3, and the RF field strength is chosen at the point which is $8 \mathrm{~cm}$ away from the sensor shell surface. Here, the RF field strength attenuation index $F$ is defined as

$$
F=\frac{B_{1,0}-B_{1, \mathrm{R}}}{B_{1,0}}
$$

where $B_{1,0}$ is the RF field strength without influence of drilling mud and formation; $B_{1, \mathrm{R}}$ is the RF field strength with influence of drilling mud and formation. 


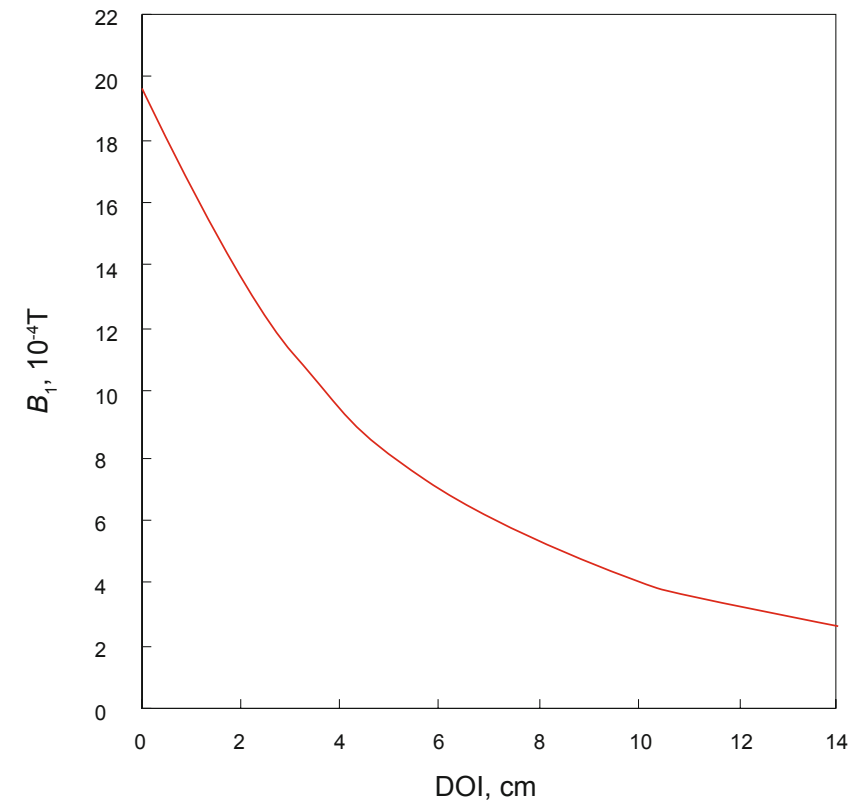

Fig. 2 RF field distribution of a centric NMR logging tool

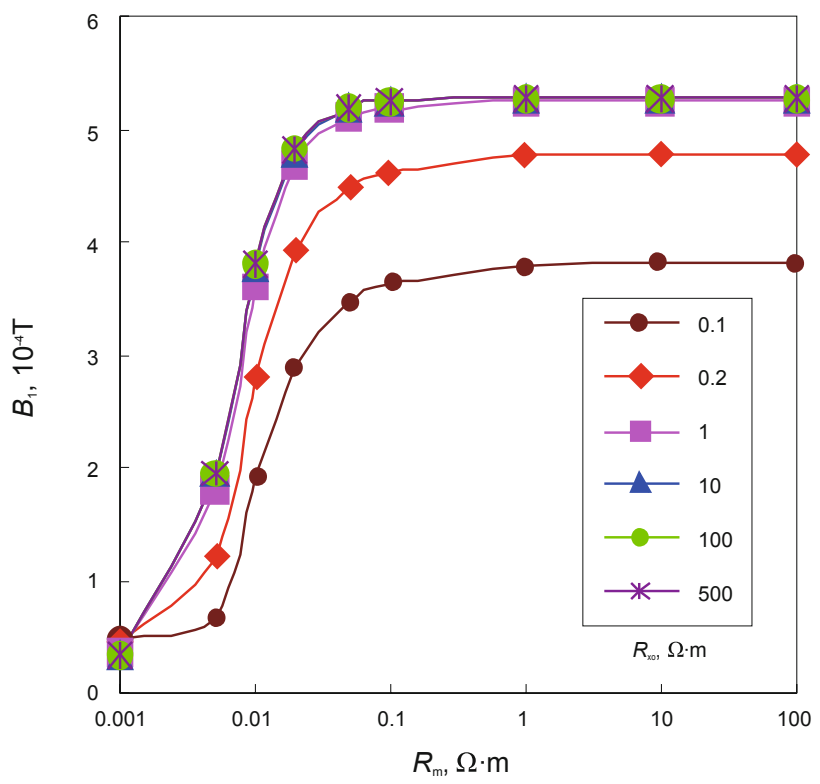

Fig. 3 The influence of water-based drilling mud-water bearing formation on the centric NMR logging tool RF field

The variation of RF field strength is plotted in Fig. 3 as a function of $R_{\mathrm{m}}$. When formation resistivity $R_{\mathrm{xo}}=1 \Omega \cdot \mathrm{m}-500$ $\Omega \cdot \mathrm{m}, \mathrm{RF}$ field strength of centric NMR logging tool keeps almost constant. When the formation resistivity $R_{\mathrm{xo}}=0.2$ $\Omega \cdot \mathrm{m}$, the RF field strength attenuation index $F=9.5 \%$. The centric NMR logging tool RF field strength decreases with a decrease of drilling mud resistivity. When the drilling mud resistivity $R_{\mathrm{m}}=0.1 \Omega \cdot \mathrm{m}-100 \Omega \cdot \mathrm{m}$, the RF field strength is almost constant. When $R_{\mathrm{m}}=0.02 \Omega \cdot \mathrm{m}$, the RF field strength attenuation index $F=8.9 \%$, which is the lowest resistivity of drilling mud allowed for centric NMR logging. When $R_{\mathrm{m}}=0.01 \Omega \cdot \mathrm{m}, F=28.3 \%$, which affects the NMR logging signal strength and SNR seriously, so correction of the RF is needed.

The influence of water-based drilling mud-oil bearing formation on the centric NMR logging tool RF field is shown in Fig. 4. The RF field strength decreases with an increase of DOI. When $R_{\mathrm{m}}=0.001 \Omega \cdot \mathrm{m}-0.02 \Omega \cdot \mathrm{m}, F$ increased with the decrease of $R_{\mathrm{m}}$; when $R_{\mathrm{m}}=0.05 \Omega \cdot \mathrm{m}-100 \Omega \cdot \mathrm{m}$, the RF field strength is constant, and the influence of drilling mud on RF field strength can be ignored.

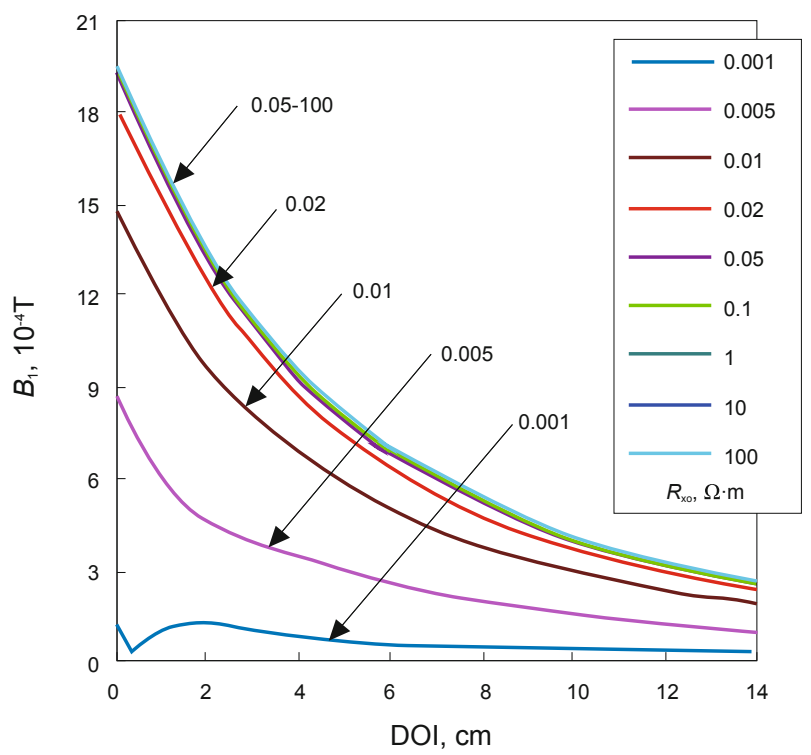

Fig. 4 The influence of water-based drilling mud-oil bearing formation on the centric NMR logging tool RF field

Because the NMR logging tool sensitive volume extends out to $8 \mathrm{~cm}$ away from borehole wall, the RF has to penetrate the formation within the sensitive volume. As shown in Fig. 5 , the influence of oil-based drilling mud-water bearing formation on the centric NMR logging tool RF field is plotted as a function of $R_{\mathrm{xo}}$. The RF field strength decreases with a decrease of formation resistivity. When $R_{\mathrm{xo}}=1 \Omega \cdot \mathrm{m}-100$ $\Omega \cdot \mathrm{m}$, RF field strength is constant; when $R_{\mathrm{xo}}<1 \Omega \cdot \mathrm{m}$, RF field strength decreases with the decrease of formation resistivity, and $F$ is up to $9.47 \%$ when $R_{\text {хо }}=0.2 \Omega \cdot \mathrm{m}$.

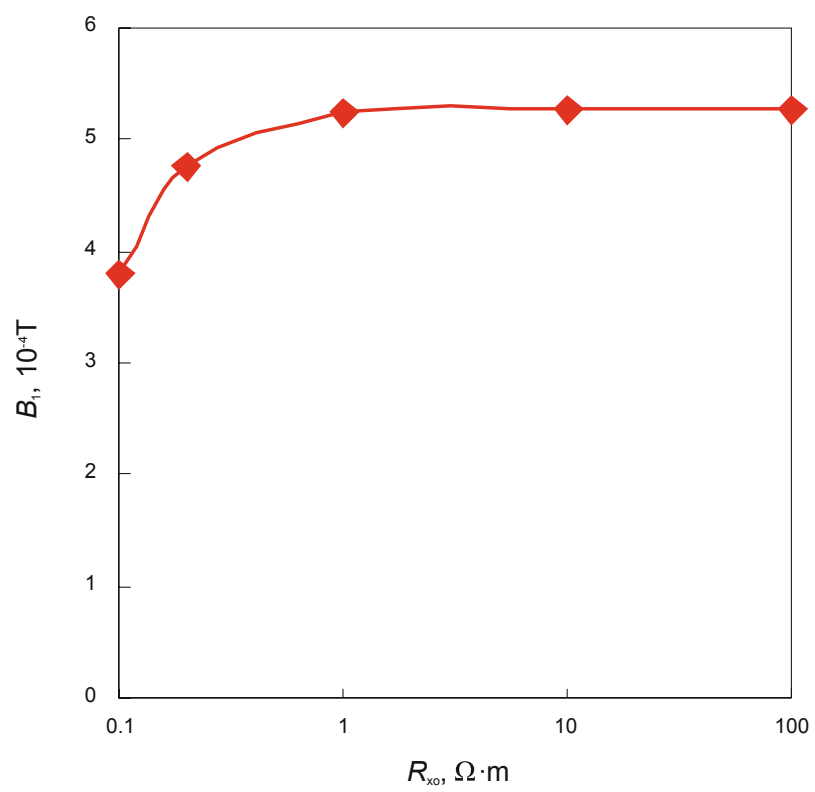

Fig. 5 The influence of oil-based drilling mud-water bearing formation on the centric NMR logging tool RF field 


\subsection{Eccentric NMR logging tools}

The influence of water-based drilling mud-water bearing formation on the eccentric NMR RF field is plotted in Fig. 6 as a function of $R_{\mathrm{m}}$. Because eccentric NMR logging tool antenna has a wide angle, and the size of borehole is bigger than the NMR sensor size, a part of the RF field still has to penetrate drilling mud to get to the formation. The results show that when $R_{\mathrm{m}}=0.01 \Omega \cdot \mathrm{m}, F=4.67 \%$ which is much lower than that of centric NMR logging tool $(F=27.95 \%)$ at the same condition.

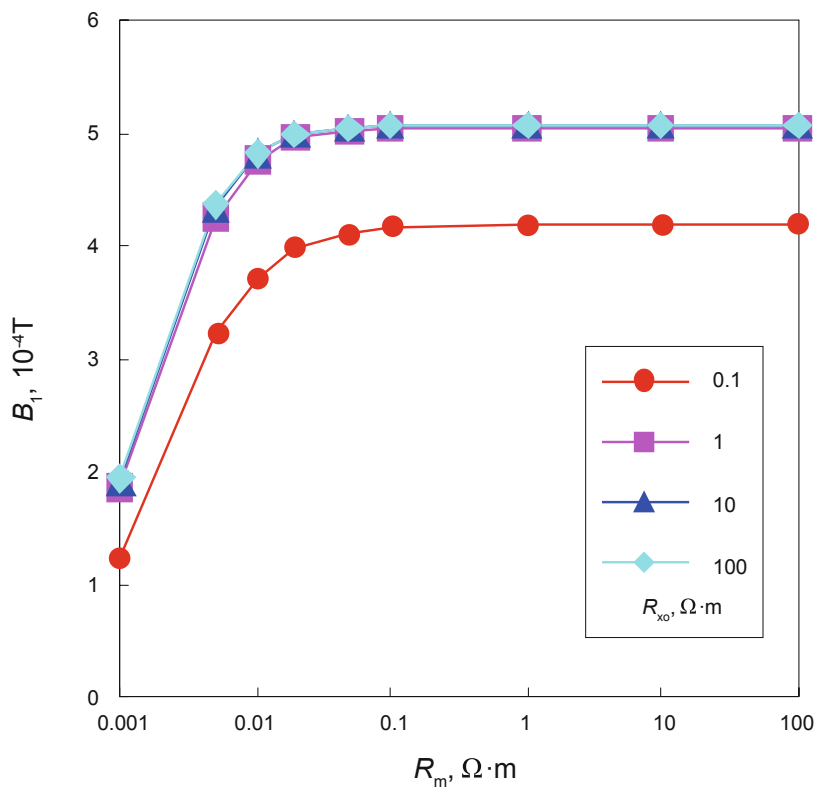

Fig. 6 The influence of water-based drilling mud - water bearing formation on the eccentric NMR logging tool RF field

The RF field strength of the eccentric NMR tool is affected mainly by formation resistivity. Fig. 7 shows the influence of formation resistivity and drilling mud resistivity on the RF field. When the model is water-based drilling

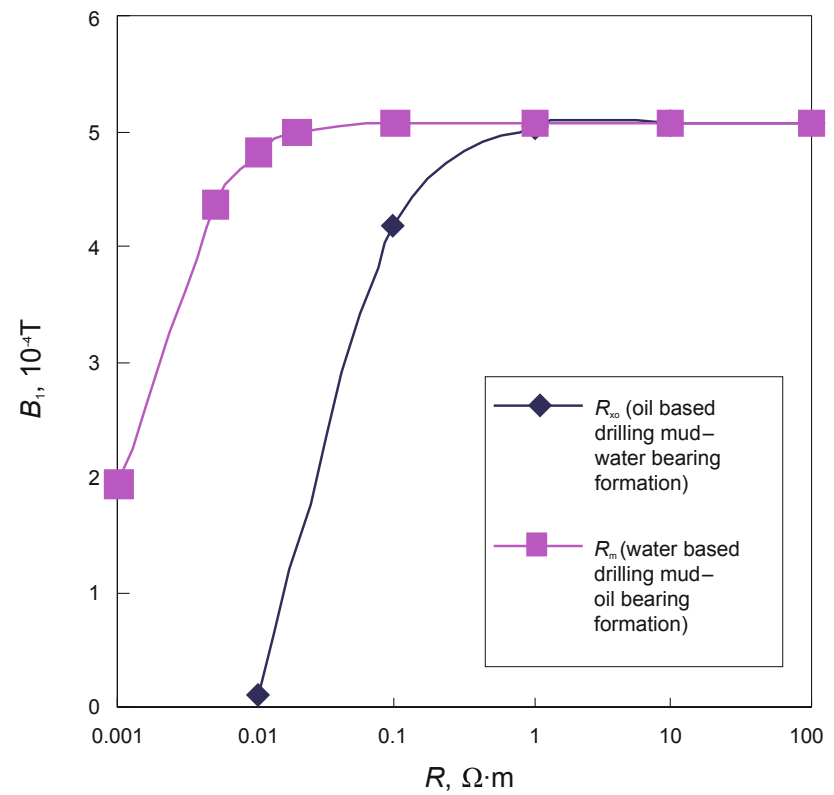

Fig. 7 The influence of formation resistivity and drilling mud resistivity on the eccentric NMR RF field mud-oil bearing formation, and $R_{\mathrm{m}}=0.01 \Omega \cdot \mathrm{m}$, the RF field strength is constant; when the model is oil-based drilling mud-water bearing formation, and $R_{\text {xo }}=0.1 \Omega \cdot \mathrm{m}$, RF field strength decreased obviously, and $F=17.5 \%$.

\subsection{Drilling mud and formation resistivity influence correction method}

According to the simulation results and analysis above, drilling mud and formation resistivity have significant attenuation effects on the NMR logging tool RF field and these effects can be indicated by the attenuation index $F$. The NMR logging tool RF field is calibrated on the ground in order to get $B_{1,0}$ which is the standard value of correction before correcting the NMR logging tool RF field for different drilling mud and formation resistivity. Then attenuation index $F$ is used to correct the RF field. The correction method of drilling mud and formation resistivity influence on the NMR logging tool RF field is proposed as

$$
B_{1, \mathrm{C}}=B_{1,0} /(1-F)
$$

where $B_{1, \mathrm{C}}$ is the RF field after correction; $B_{1,0}$ is the RF field without influence; $F$ is the attenuation index (see Table 1 and Table 2).

Table 1 The attenuation index of the centric NMR logging tool RF field

\begin{tabular}{ccccccc}
\hline \multirow{2}{*}{$R_{\mathrm{m}}, \Omega \cdot \mathrm{m}$} & \multicolumn{7}{c}{$R_{\mathrm{xo}}, \Omega \cdot \mathrm{m}$} \\
\cline { 2 - 7 } & 0.1 & 0.2 & 1 & 10 & 100 & 500 \\
\hline 0.001 & 0.906 & 0.916 & 0.932 & 0.937 & 0.937 & 0.937 \\
0.005 & 0.871 & 0.770 & 0.659 & 0.633 & 0.630 & 0.630 \\
0.01 & 0.634 & 0.469 & 0.314 & 0.282 & 0.279 & 0.279 \\
0.02 & 0.455 & 0.263 & 0.113 & 0.089 & 0.087 & 0.087 \\
0.05 & 0.344 & 0.151 & 0.030 & 0.016 & 0.015 & 0.015 \\
0.1 & 0.309 & 0.120 & 0.014 & 0.005 & 0.004 & 0.004 \\
1 & 0.280 & 0.097 & 0.005 & 0.000 & 0.000 & 0.000 \\
10 & 0.278 & 0.095 & 0.005 & 0.000 & 0.000 & 0.000 \\
100 & 0.277 & 0.095 & 0.004 & 0.000 & 0.000 & 0.000 \\
500 & 0.277 & 0.095 & 0.004 & 0.000 & 0.000 & 0.000 \\
\hline
\end{tabular}

Table 2 The attenuation index of the eccentric NMR logging tool RF field

\begin{tabular}{cccccc}
\hline \multirow{2}{*}{$R_{\mathrm{m}}, \Omega \cdot \mathrm{m}$} & \multicolumn{5}{c}{$R_{\mathrm{xo}}, \Omega \cdot \mathrm{m}$} \\
\cline { 2 - 6 } 0.001 & 0.753 & 0.631 & 0.619 & 0.618 & 0.618 \\
0.005 & 0.359 & 0.157 & 0.141 & 0.140 & 0.140 \\
0.01 & 0.263 & 0.061 & 0.048 & 0.047 & 0.047 \\
0.02 & 0.214 & 0.022 & 0.014 & 0.013 & 0.013 \\
0.05 & 0.186 & 0.008 & 0.003 & 0.002 & 0.002 \\
0.1 & 0.177 & 0.004 & 0.000 & 0.000 & 0.000 \\
1 & 0.169 & 0.002 & 0.000 & 0.000 & 0.000 \\
10 & 0.168 & 0.002 & 0.000 & 0.000 & 0.000 \\
100 & 0.168 & 0.002 & 0.000 & 0.000 & 0.000 \\
\hline
\end{tabular}




\subsection{Influence mechanism analysis of sodium ions and correction method}

Sodium ions that produce NMR signals are about 0.5 $\mathrm{cm}$ away from the NMR sensor shell. For eccentric NMR logging tools, the antenna is close to the borehole wall and hence formation is $<0.5 \mathrm{~cm}$ away from the eccentric NMR sensor shell. So, the analysis and correction are only required to allow for the influence of sodium ions in drilling mud on centric NMR logging tools, but not on eccentric tools. According to NMR signal theory, the induced voltage (Hoult and Richards, 1976; Hürlimann and Griffin, 2000) in the coil can be described as

$$
V_{x, y}(t)=\frac{2 \chi}{\mu_{0}} \int \mathrm{d} r \Phi(r) \frac{\omega_{1}(r)}{I} F\left(\Delta \omega_{0}(r)\right) m_{x y}(r t)
$$

where $\chi$ is the nuclear susceptibility; $\Phi(r)$ is local porosity; $m_{x y}(r t)$ is the local transverse magnetization. According to Eq. (8), the NMR signal strength is proportional to the transverse magnetization. The macroscopic magnetization is determined by Curie's Law as

$$
M_{0}=N \frac{\gamma^{2} h^{2}(I+1)}{3\left(4 \pi^{2}\right) k T} B_{0}
$$

where $N$ is nuclei number per unit volume; $k$ is Boltzman's constant; $T$ is absolute temperature (Kelvin), $h$ is Planck's constant; $I$ is the spin quantum number of the nucleus. For hydrogen, $I=1 / 2$, for sodium ions, $I=3 / 2$. The NMR signals coming from sodium ions are proportional to the sodium ion concentration.

When $f=766 \mathrm{kHz}$, the normalized NMR signals coming from hydrogen and sodium can be obtained by numerical simulation. The normalized hydrogen signals $\left(\right.$ Signal $\left._{\mathrm{H}}\right)$ and sodium signals $\left(\right.$ Signal $_{\mathrm{Na}}$ ) are plotted in Fig. 8 as a function of $x$ and $y$. The ratio of sodium signals to hydrogen signals is Signal $_{\mathrm{Na}} /$ Signal $_{\mathrm{H}}=0.592: 1$, where Signal $_{\mathrm{Na}}$ and Signal $_{\mathrm{H}}$ are obtained at $100 \%$ content respectively.

According to the analysis above, the ratio of Signal ${ }_{\mathrm{Na}}$ to total signal in NMR logging can be calculated as

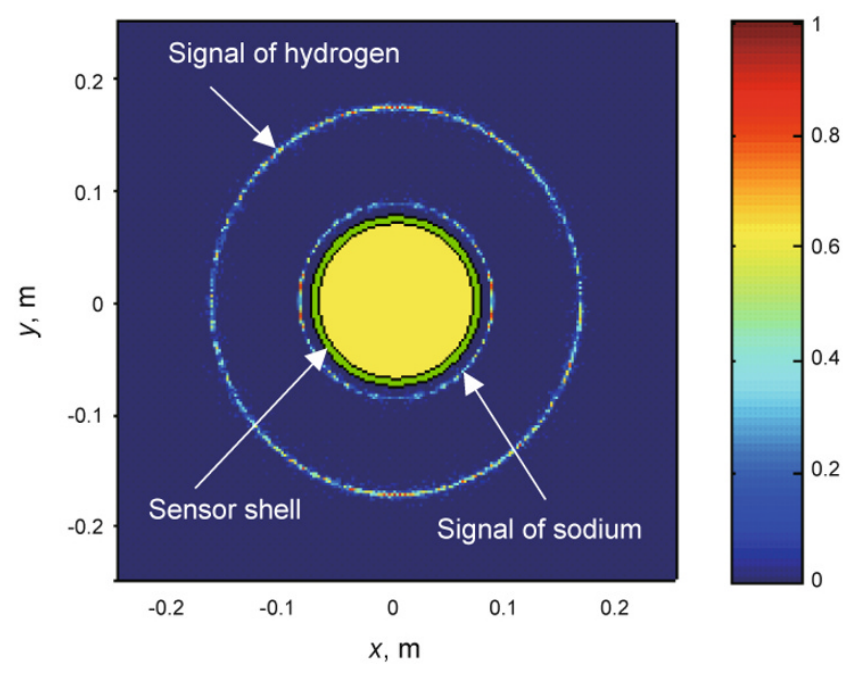

Fig. 8 NMR signals of water and sodium ions

$$
C=\frac{0.592 \times S}{1+0.592 \times S}
$$

where, $S$ is the content of sodium ions in drilling mud, which can be obtained by measurement. At $100{ }^{\circ} \mathrm{C}, 101 \mathrm{KPa}$, solubility of $\mathrm{NaCl}$ in water is about $392 \mathrm{~g} / \mathrm{kg}$, and $C=31.8 \%$.

In NMR logging, the signals coming from formation fluid are described as

$$
\text { Signal }_{\mathrm{C}}=\left(1-\text { C) } \text { Signal }_{\mathrm{m}}\right.
$$

where, Signal ${ }_{\mathrm{c}}$ is NMR logging data after correction, Signal ${ }_{\mathrm{m}}$ is actual measurement data. This correction method is applied when sodium signals are bigger than noise Signal $_{\mathrm{Na}}^{\prime}>$ Noise, Signal ${ }_{\mathrm{Na}}$ and Noise are obtained from the same NMR logging data. That is because if Signal $<$ Noise, the sodium signals have become noise.

\section{Conclusions}

The influence of drilling mud and formation on NMR logging can be analyzed by numerical simulation. Low resistivity drilling mud and formation have a great attenuation effect on the centric NMR logging tool RF field, and the attenuation index increases with a decrease of drilling mud and formation resistivity. When $R_{\mathrm{m}}=0.02 \Omega \cdot \mathrm{m}$, the RF field attenuation index of the centric NMR logging tool is $F=8.9 \%$; when $R_{\mathrm{xo}}=0.2 \Omega \cdot \mathrm{m}, F$ is up to $9.47 \%$. The eccentric NMR logging tool is mainly influenced by formation resistivity.

When $R_{\mathrm{m}}=0.1 \Omega \cdot \mathrm{m}$, the RF field attenuation index is $F=17.5 \%$. According to the analysis, the RF field correction method has been proposed and this method is applied to attenuation indexes less than $10 \%$. In actual application, when the attenuation index is bigger than $10 \%$, a mud excluder should be used to eliminate or reduce the influence of drilling mud and formation. For centric NMR logging tools, the signals coming from sodium ions can be up to $31.8 \%$ of total signals, and the corresponding correction method is applied when sodium signals are bigger than noise. The influence of fluid on NMR logging tools and the NMR logging response characteristics can be researched further by experiments, which is our next plan.

\section{Acknowledgements}

This work was supported by the National Natural Science Foundation of China (No.41074102) and China International Science and Technology Cooperation (No.2009DFA61030).

\section{References}

Chen S H and Hursan G. A new method for estimating formation water $R_{\mathrm{w}}$ using NMR logging data. SPWLA 51th Annual Logging Symposium, 19-23 June 2010, Perth, Australia (SPWLA TTT)

Coates G R, Xiao L Z and Prammer M G. NMR Logging Principles and Applications. Houston: Halliburton Energy Services. 1999

Ferris J A, Tutunjian P N and Vinegar H J. Nuclear magnetic resonance imaging of sodium-23 in cores. The Log Analyst. 1993. 34(3): 11-19

Headley L C. Nuclear magnetic resonance relaxation of ${ }^{23} \mathrm{Na}$ in porous 
media containing $\mathrm{NaCl}$ solution. Journal of Applied Physics. 1973. 44(7): 3118-3121

Hoult D I and Richards R E. The signal to noise ratio of the nuclear magnetic resonance experiment. Journal of Magnetic Resonance. 1976. 24(1): 71-85

$\mathrm{Hu} \mathrm{H} \mathrm{T}$ and Xiao L Z. Investigation characteristics of NMR wireline logging tools. Chinese Journal of Magnetic Resonance. 2010. 27(4): 572-583 (in Chinese)

Hu H T, Xiao L Z and Wu X L. A method for evaluating the performance of NMR logging device. Chinese Journal of Magnetic Resonance. 2011. 28(1): 76-83 (in Chinese)

Hürlimann M D and Griffin D D. Spin dynamics of Carr-PurcellMeiboom-Gill-like sequences in grossly inhomogeneous $B_{0}$ and $B_{1}$ fields and application to NMR well logging. Journal of Magnetic Resonance. 2000. 143(1): 120-135

Mardon D, Prammer M G, Taicher Z, et al. Improved environmental corrections for MRIL pulsed NMR logs run in high-salinity boreholes. SPWLA 36th Annual Logging Symposium, 26-29 June 1995, Paris, France (SPWLA DD)

Prammer M G, Bouton J, Drack E D, et al. A new multiband generation of NMR logging tools. SPE Reservoir Evaluation \& Engineering. 2001. 4(1): 59-63 (SPE 69670-PA)

Reiderman A and Beard D. Side-looking NMR probe for oil well logging. U.S.patent: 6580273. 2003

Sun B Q and Dunn K J. Two-dimensional nuclear magnetic resonance petrophysics. Magnetic Resonance Imaging. 2005. 23(2): 259-262

Sun B Q, Dunn K J and Clinch S. Inversion along the depth dimension to enhance the continuity of multi-dimensional NMR logs. SPWLA 51th Annual Logging Symposium, 19-23 June 2010, Perth, Australia (SPWLA YY)

Sun B Q, Skalinski M and Dunn K J. NMR $T_{2}$ inversion along the depth dimension. AIP Conference Proceedings. 2009. 1081: 87-90

Wang X W, Xiao L Z, Xie R H, et al. Study of NMR porosity for terrestrial formation in China. Science in China Series G. 2006. 49(3): 313-320

Xiao L Z. Some important issues for NMR logging applications in China. Well Logging Technology. 2007. 31(5): 401-407 (in Chinese)

Xiao L Z, Liao G Z, Xie R H, et al. Inversion of NMR relaxation measurements in well logging. In: Magnetic Resonance Microscopy. Weinheim: WILEY-VCH Verlag GmbH \& Co. KGaA. 2009. 501517

Xie Q M, Xiao L Z and Liao G Z. Application of SURE algorithm to echo train de-noising in low field NMR logging. Chinese Journal of Geophysics. 2010. 53(11): 2776-2783 (in Chinese)

Xie R H and Xiao L Z. The $\left(T_{2}, D\right)$ NMR logging method for fluids characterization. Chinese Journal of Geophysics. 2009. 52(9): 24102418 (in Chinese)

Xie R H, Xiao L Z and Dunn K J. NMR logging porosity activation and data processing method. Chinese Journal of Geophysics. 2006. 49(5): 1567-1572 (in Chinese)

Xie R H, Xiao L Z, Wang Z D, et al. The influence factors of NMR logging porosity in complex fluid reservoir. Science in China Series D: Earth Sciences. 2008. 51(Supp.II): 212-217

(Edited by Hao Jie) 